\title{
Discovering the effect of RES on risk premia in electricity markets
}

\author{
$\underline{\text { S. Stefani }}{ }^{\text {a }}$ P. Falbo ${ }^{\text {b }}$ and D. Felletti ${ }^{\text {a }}$ \\ ${ }^{a}$ Department of Statistics and Quantitative Methods, Università Milano Bicocca, Milano (Italy) \\ Email: silvana.stefani@unimib.it \\ ${ }^{b}$ Department of Economics and Management, Università di Brescia, Brescia (Italy)
}

\begin{abstract}
This paper is part of a broader project aimed at discovering the effect of Renewable Energy Sources (RES) on electricity markets. The recent massive RES production in Europe is relatively recent: it started since 2009-2010 due to system of incentives introduced in almost all European countries. Nowadays, the technologies are consolidated and even though the incentive system has stopped (due also to the economic crisis), RES produce energy and have contributed at lowering (at least in the wholesale markets) prices. However, the effect of RES production on risk premia is still quite elusive and requires deeper analysis. In this exploratory and preliminary paper, we develop an ex post analysis on risk premia on the Italian futures market. The peculiarities of the electricity markets make electricity futures very different than financial or commodity futures. In fact, it is well known that a consequence of non-storability of electricity is that the only possible delivery in a forward or futures contract is through a supply over a period of time. The entire lifecycle of a standard futures/forward contract on electricity can be divided in a trading period and a delivery period. Differently from the classical case, the convergence of futures price to spot prices does not hold here. Indeed, at the end of the trading period futures expire, yet the spot price continues evolving during all the delivery period. Parties can open positions on forward and futures contracts only before the delivery period. At maturity $(\mathrm{T})$, that is at the end of the delivery period $\mathrm{H}$, contracts expire. Our work contributes to the existing literature on futures in electricity markets by analyzing empirically the deviation of futures prices from observed spot prices. The analysis is carried on the Italian forward base load monthly contracts (20082012). The results show, case by case, a clear non convergence of futures to the underlying spot prices or average of them (see Figure).
\end{abstract}

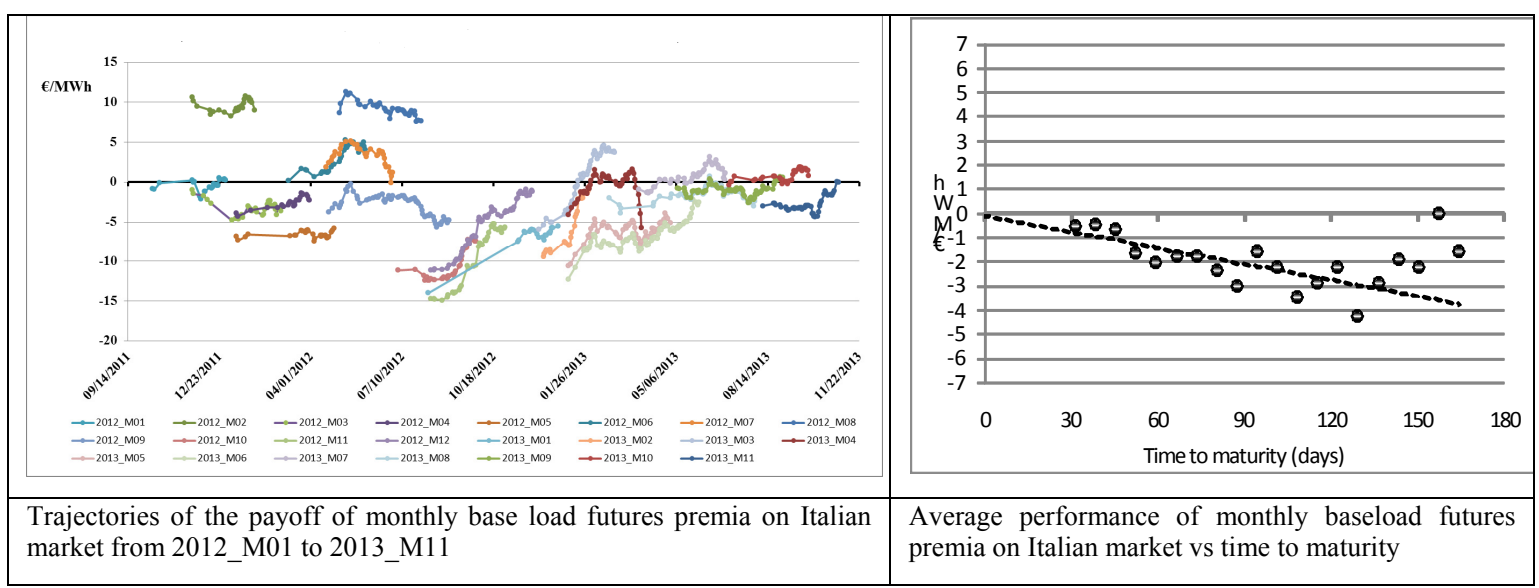

However, at an aggregate level, a positive risk premium is found, which is somehow coherent with findings in the literature (see Figure). Moreover, given the absence of convergence of futures to spot prices at the end of trading period, a positive variance of the payoff is found at delivery. The results show that more research should be done on modelling average spot prices and futures, since most of the rules valid for other financial and commodity markets do not hold here. In fact, the underlying price is the average of ex post prices over the delivery period, which can last one month, three months or even one year. Modelling such a price can be even more challenging than modelling spot price and we know that modelling spot prices in electricity markets is a demanding task and still in progress.

Keywords: Risk premia, electricity markets, futures and forwards 
Falbo et al., Discovering the effect of RES on risk premia in European electricity markets

\section{INTRODUCTION}

The restructuring process of the electricity sector in any countries worldwide has been accompanied by the opening of competitive spot electricity markets. Prior deregulation, electricity prices were relatively steady. After deregulation and introducing competition in wholesale and retail electricity markets, electricity prices have been among the most volatile of any traded commodity. Electricity is a flow rather than a stock commodity: it is produced and consumed instantaneously and continuously. Once generated, electricity cannot be stored in warehouses like the great majority of commodities, and at any moment demand has to be met by electricity produced at the same time. This makes electricity produced on the third hour of the day a different commodity than the electricity produced the fourth hour of the day. So, electricity prices are primarily driven by spot demand and supply. As far as the demand is concerned, demand for electricity fluctuates daily, according to peak or off-peak hours, day and night. Demand is highly local. Spain has a different demand profile than Germany. North Italy has a different demand profile as South Italy. Moreover, electricity demand in the short term market is fairly inelastic and cannot be met clearing the inventory. Therefore, unexpected demand shocks due, for example, to extreme weather conditions (particularly cold or hot days) or additional need of power, typically Christmas holidays, cause an upward shift in the demandsupply curve. As an example, in Figure 1, peaks occurred in the BPX Belgium baseload price between Feb 9, 2012 and Feb 15, 2012, with minor increases in the other Western Central Europe baseload markets (serving Germany, France, Austria). The BPX price increased from an average of $60 € / \mathrm{MWh}$ to over $360 € / \mathrm{MWh}$.

This peculiar characteristics makes pricing of futures and forward one of the most interesting and challenging questions among all the financial markets. Since the cost-of-carry approach as a non arbitrage condition cannot be applied here, it is recognized that pricing futures and forwards is not feasible with the classical and accepted models that are currently applied to commodities and financial products. To give an idea, in "ordinary" financial series volatility is about $10-20 \%$ of average prices, in commodities can reach $80-100 \%$, in some electricity prices it can reach $300-450 \%$ and even more. As an example, in Australia the average spot price is around $\$ 40-70$ per $\mathrm{MWh}$, and it can go up to $\$ 12,000$. Thus, understanding the nature of the deviation of future prices from expected spot prices (the so called risk premium) is particularly crucial, given the need for all players in electricity markets (generators, utilities, final consumers) to hedge against the extreme volatility. However, results are so far rather elusive.

The question is still open, in particular after the massive introduction of RES in electricity production. RES have introduced on one hand, even more volatility, due to the intermittence of the two main RES sources (sun and wind), but on the other hand have substantially increased supply, reducing the peak size. So, a thorough analysis is required to ascertain the effect of RES into the price system (in Germany we have recently experienced negative wholesale prices). Before analyzing the impact of RES into risk premia, we decided first to concentrate in the empirical observation of risk premia per se. This preliminary work contributes to the existing literature on futures in electricity markets by analyzing empirically the deviation of futures prices from observed spot prices. The analysis is carried on the Italian forward base load monthly contracts (20082012). The results show the presence of an aggregate positive risk premium. However, case by case, a clear non convergence of futures to the underlying spot prices (or average of them) is shown. Moreover, a positive variance of the payoff is found at delivery. Of the vast literature on price modelling, risk premia and risk management, we quote Eydeland and Geman (1999), Routledge et al (2000), Bessembinder and Lemmon (2002), Shawky et al (2003), Geman (2005), Geman and Roncoroni (2006), Douglas and Popova (2008), Pietz (2009), Bloys Van Treslong and Huisman (2010), Botterud et al (2010), Deng and Oren (2006), Falbo et al (2010a, 2010b, 2015), Lucia and Torrò (2011), Mayer et al. (2011), Huisman and Kilic (2012), Bunn and Chen (2013), Hildmann et al (2014). 


\section{ELECTRICITY MARKETS}

\subsection{Futures and forward contracts}

Due to the extreme volatility of electricity spot prices, derivative instruments to essential for hedging. In particular, electricity futures and forwards may help generators, consumers and marketers to manage volatility, but also introduce risks of their own. Among other sources of risk, in Falbo et al (2010a), the perverse effect on hedging strategies of a poorly designed spot price index is described. A usual way to hedge against price uncertainty in electricity markets is signing forwards. In fact, less than $5 \%$ of the whole European electricity is traded on the spot markets (Wu et al., 2002; Routledge et al., 2000). Since forwards allow to sell production in advance at a given price, but do not hedge against fuel cost volatility, efficient risk management strategies suggest to reduce the total risk by selling also in the spot market (Falbo et al., 2010b).

A consequence of non-storability of electricity is that the only possible delivery in a forward or futures contract is through a supply over a period of time. The entire lifecycle of a standard futures/forward contract on electricity can be divided in a trading period and a delivery period. Differently from the classical case, the convergence of futures price to spot does not hold here. Indeed at the end of the trading period futures prices expire, yet the spot price continues evolving during all the delivery period. Parties can open positions on forward and futures contracts only before the delivery period. At maturity $(\mathrm{T})$, that is at the end of the delivery period $\mathrm{H}$, contracts expire. If physical delivery was agreed, the seller ends up his obligation, by supplying the due quantity of energy. If cash settlement was agreed, payoff calculation is possible, and the corresponding payment concludes the contract.

We name the spot index price of electricity of day $\mathrm{t}$ as $p_{t}$. We assume that it is calculated as an arithmetic average of the 24 hourly prices:

$$
p_{t}=\frac{1}{24} \sum_{h=1}^{24} p_{t, H}
$$

Arithmetic average is the standard way to calculate the daily index price in most electricity markets worldwide, even though exceptions exist (see on this topic Falbo et al. 2010a). The price fixed in a futures contract for delivery of $1 \mathrm{MWh}$ on period $\mathrm{H}$ (month, quarter, year) agreed on day $t$ is referred as futures price and it is labeled as $f_{t, H}$. As already mentioned, in most cases in a futures contract at the end of the trading period the parties agree not to settle their contract through physical delivery, but prefer a cash settlement. In both cases the profit/loss is calculated as the difference between the average electricity price observed during $\mathrm{H}$ and $f_{t, H}$. In particular letting the ex-post average price of electricity of period $\mathrm{H}, \bar{p}_{\mathcal{H}}$, be as

$$
\bar{p}_{H}=\frac{1}{|\mathrm{H}|} \sum_{(t, H) \in H} p_{t, H}
$$

the payoff of a futures contract signed in $\mathrm{t}$ for period $\mathrm{H}$ is

$$
y_{\tau, H}=y_{T(H)-t, H}=\bar{p}_{H}-f_{t, H}
$$

where $\tau=T(H)-t$ is the time to maturity, that is the number of days between the last delivery date of period $H$ (i.e. $T(H)$ ) and $t$. $\tau$ can never be less than the length of $\mathrm{H}$. Such a payoff is sometimes referred in the literature as the risk premium, even though we do not agree on such a definition. Indeed, in absence of a meaningful hypothesis to differentiate the buyers from the sellers, from a financial point of view, in a futures contract both parties have a symmetric position, with no explicit risk transfer from one party to the other.

\section{THE EMPIRICAL ANALYSIS}

\subsection{The data}

In this paper we analyze the time series of the real-time forward contracts observed in Italy from January 2008 up to November 2013. The forward electricity market in Italy captures by far a larger quota of the total volume of the contracts for delivery than the current futures market. Real time quotations are accessible to through a brokerage trading platforms, where the bids of producers and retailers are collected and shared.

The values of $y_{t, H}$ have been calculated on a daily basis. In particular $f_{t, H}$ have been identified with the latest quotation of day $t$, as long as a deal (at least) occurred in $t$. 
Falbo et al., Discovering the effect of RES on risk premia in European electricity markets

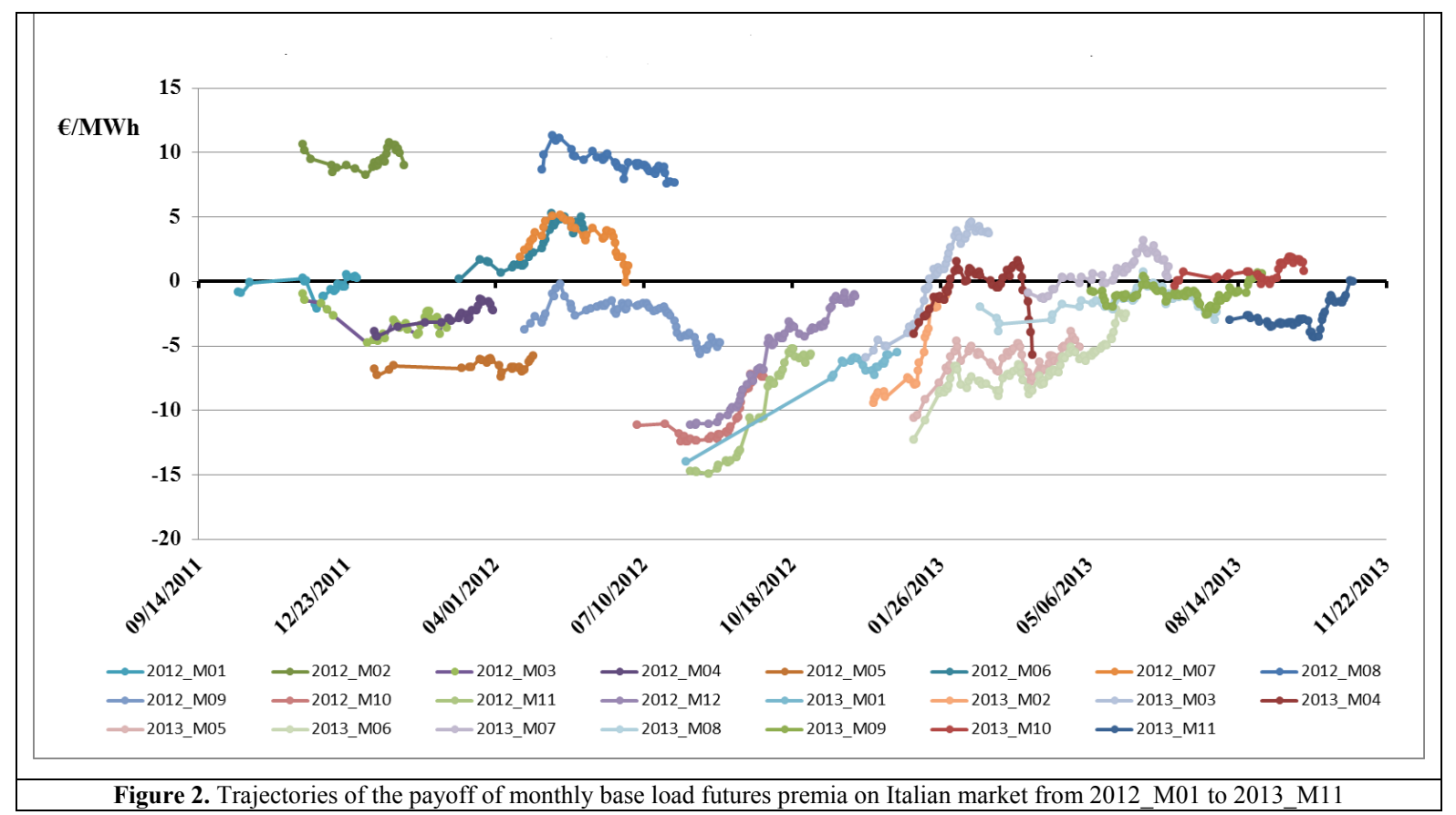

Figure 2 shows several trajectories of the premium process calculated ex-post for the (monthly) delivery periods from Jan-2012 to Nov-2013. We can distinguish different cases. The expected behavior of these trajectories, under the hypothesis of symmetric risk aversion, are those of Jan-2012 (2012_M01 in the figure; it matches immediately the price and moves around it) or Jul-2012 (similar to Jan-2012 but with a larger volatility). Dec-2012, Feb-2013 and Nov-2013 are also "regular": they start far from zero, but approach the correct value as the trading period finishes. However the trajectory of Mar-2013 shows a clear trend, so that the trajectory crosses the target. Then there are contracts that never match the target like Feb-2012 and Aug2012 (typically this is due to unexpectedly high spot prices during the delivery period). Finally there are cases, like Sep-2012, of diverging trend moving the trajectory far from 0, and totally odd cases like Apr2013. For further evidence, in Fig. 3 each candle summarizes the series of futures prices for each monthly contract H. According to candlestick graphs, black candles represents the case of a trajectory where

$$
y_{\tau}<y_{t_{0}} \text { i.e. } f_{\tau, H}>f_{t_{0}, H}
$$

where $t_{0}$ is the starting day of futures trading while the opposite applies to white color. The surprising cases are therefore represented by the black candles lying below zero, and the white ones lying above, since in both cases we are faced with trajectories which kept diverging away from zero during their trading period. These contracts, which are not a few, forecasted the spot price better at large times to maturities than at the end of the trading period.

Figures 4 and 5 show the $\mathrm{y} \tau$ values for the $\mathrm{H}$ periods analyzed here. In particular, Fig. 5 focuses on monthly periods, while Fig. 4 shows quarterly periods. Both figures show that future prices do not really match the spot prices and that uncertainty persists in time. This is particularly true for monthly contracts. Observing the values of $\mathrm{y} \tau$ separately for each period $H$, it is apparent that futures prices tend not to be good forecast of $\bar{p}_{i f}$. However we must also consider the average

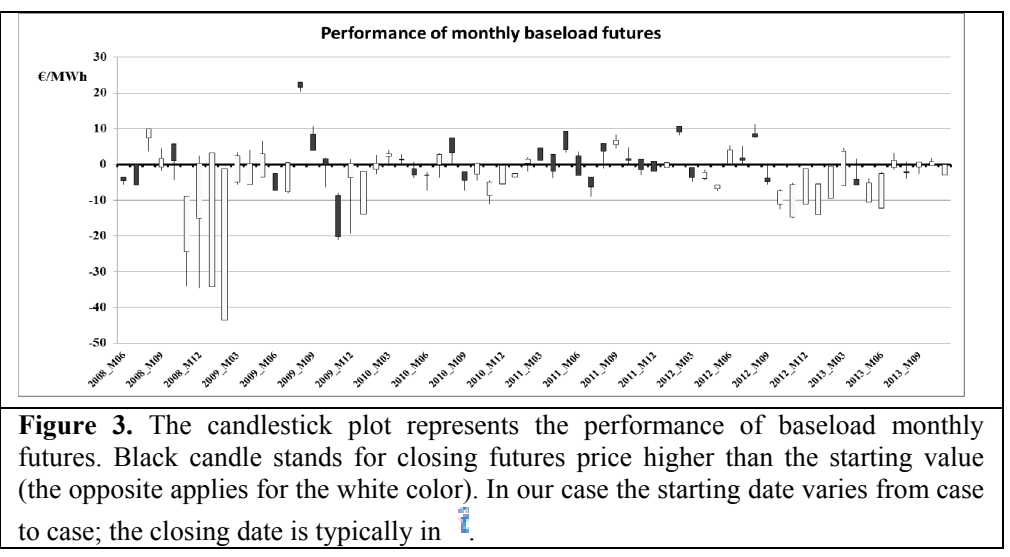
behavior of $y_{\tau}$, that is the process of the payoff resulting from the average payoff over all the future contracts. To check if futures prices are unbiased estimators of the average spot price during delivery, we should check the hypothesis

$$
f_{t, H}=E_{t}\left[\bar{p}_{H}\right]
$$


Falbo et al., Discovering the effect of RES on risk premia in European electricity markets

Indeed, in competitive markets the buyer and the seller will agree to fix a futures price which is the expectation of the average spot price during delivery. Under this symmetry hypothesis, the expected value of $y_{t, H}$ should be zero for both. We consider the following simple linear model for the payoff of a futures contract $\mathrm{H}$ :

$$
E_{t}\left[\bar{p}_{H}\right]-f_{t, H}=r_{H}(T(H)-t)+b_{H}
$$

where $b_{H}$ is a idiosyncratic random variable with zero expected value and $r_{H}$ is a constant which reflects the risk premium of futures prices. Observe that in the absence of any difference in the risk aversion between buyers and sellers, no risk premium should be established in the market, and (4) coincides with (3).

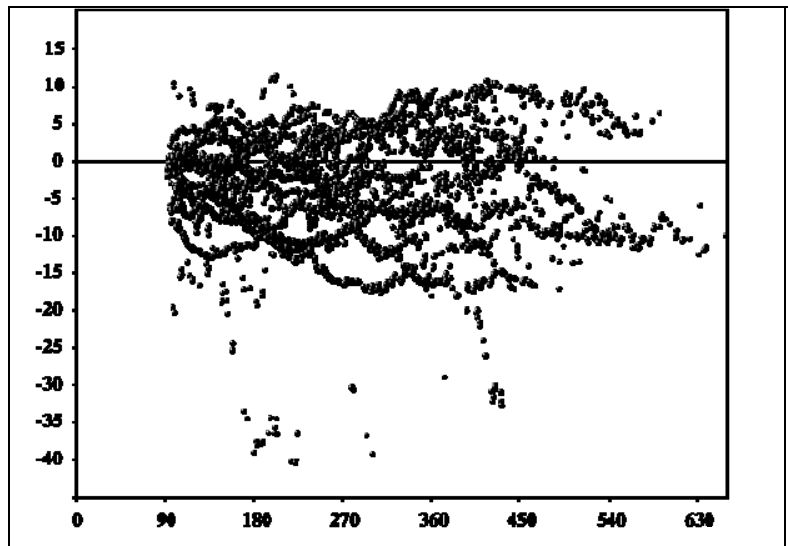

Figure 4. Performance (€/MWh) of quarterly baseload contracts on Italian market from Q4 2008 to Q3 2013 vs time to maturity (days).

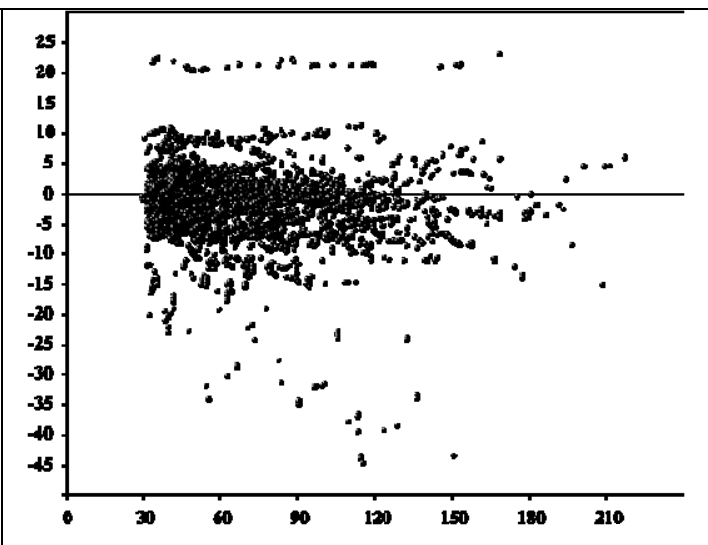

Figure 5. Performance (€/MWh) of monthly baseload contracts on Italian market from Q4 2008 to Q3 2013 vs time to maturity (days).

Assuming that the expectation of $\bar{p}_{M}$ at time $t$ coincides with its ex-post realization, the equivalent empirical model of (4) is

$$
y_{\tau, H}=r_{H}(T(H)-t)+b_{H}+\epsilon_{t}
$$

The following Table 1 reports the regression results obtained for all the monthly futures contracts analyzed here:

Table 1. Regression results for all futures contracts

\begin{tabular}{|l|c|c|c|c|}
\hline Coefficient & \#cases & \# cases $\neq 0$ significantly & Mean & Std deviation \\
\hline$r_{H}$ & 66 & 20 & -0.0419 & 0.109 \\
\hline$b_{H}$ & 66 & 15 & 0.916 & 6.774 \\
\hline
\end{tabular}

In the majority of cases (46 over 66) the estimate of parameter $r_{H}$ is not significantly different from zero, as well as $b_{H}(51$ over 66$)$. At the same time $b_{H}$ is not different from zero also on average, as it can be observed comparing its mean with the standard deviation. Notice that $b_{H}$ was indeed assumed as a zero mean random variable. The payoffs of futures contracts observed case by case look like trajectories with no trend (in most cases), exactly as Fig. 2 shows. However, let us consider the aggregate version of the expected payoff, i.e.

$$
\left.E_{H}\left[E_{t}\left(\bar{p}_{H}\right)\right]-E_{H} \mid f_{t, H}\right\rfloor=r(T-t)
$$

Where $r$ is a coefficient reflecting the risk premium for the market overall. In particular we should expect that $r$ be zero if there if not significant different risk aversion between buyers and sellers. The estimated values of the resulting regression are in Table 2 and in Figure 6.

\begin{tabular}{|l|c|c|c|c|}
\hline \multicolumn{5}{|c|}{ Table 2. Aggregated regression results for monthly expectations } \\
\hline Coefficient & Estimate & Standard error & t-Student value & $\operatorname{Pr}(t)$ \\
\hline
\end{tabular}


Falbo et al., Discovering the effect of RES on risk premia in European electricity markets

Such a result confirms the empirical findings of the literature that there is a positive

\begin{tabular}{|l|l|l|l|l|}
\hline$r$ & -0.02207 & 0.0047 & -4.67 & 0.0002 \\
\hline$b$ & -0.1129 & 0.3633 & -0.31 & 0.7594 \\
\hline
\end{tabular}
risk premium embedded in futures prices (recall that the negative value of the coefficient $r$ is due to the fact that $y_{t}$ is defined here as $\bar{p}_{H}-f_{t, H}$ ), so that they tend to over-estimate the spot price, with the over-estimation increasing linearly with the time to maturity.

However, at the same time, we have already observed that this result does not hold observing futures contracts case by case. At the same time $b$ is not significantly different from zero, as it was expected.

We next consider the standard deviation of $y_{t}$ changes with respect to the time to maturity over all contracts. Results are in Table 3 and Fig. 7. Observe that the intercept is significantly greater than zero. This means that there is a significant residual volatility of about $3.95 € / \mathrm{MWh}$. Indeed, such a residual volatility can be attributed to the variance of $b$ (idiosyncratic error) and to that of

\begin{tabular}{|l|c|c|c|c|}
\hline \multicolumn{5}{|c|}{ Table 3. Aggregated regression results for monthly standard deviation. } \\
\hline Coefficient & Estimate & Standard error & $\begin{array}{c}t \text {-Student } \\
\text { value }\end{array}$ & $\operatorname{Pr}>(t)$ \\
\hline Std $\left(y_{t}\right)$ & 0.0332 & 0.00745 & 4.46 & 0.0003 \\
\hline Intercept & 3.95252 & 0.5723 & 6.91 & $<.0001$ \\
\hline
\end{tabular}
the residuals.

\section{FURTHER ANALYSIS ON MODELLING FUTURES PRICES}

We performed further analysis to check if futures prices follow a standard Brownian motion. Our analysis is based on Lo and Mackinlay test (1988). The test of Lo and Mackinlay leverages on the property that the variance of an increase of a Brownian motion over an interval between time $t$ and time $t+k$ should increase linearly with $k$. Results (not reported here) confirm the hypothesis of a standard Brownian random walk. Indeed, the volatility measured over the single contracts appears perfectly compatible with a Brownian

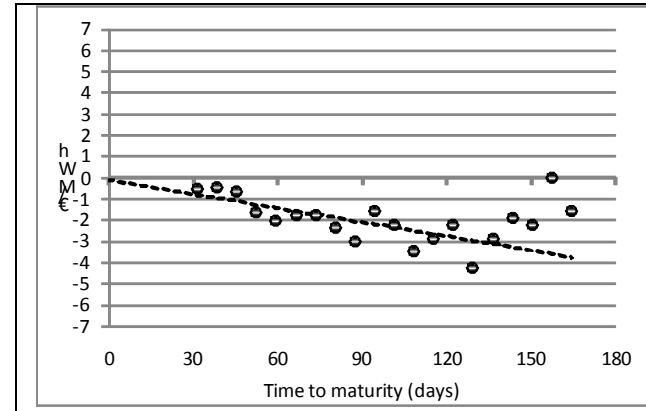

Figure 6. Average performance of monthly baseload futures premia on Italian market vs time to maturity.

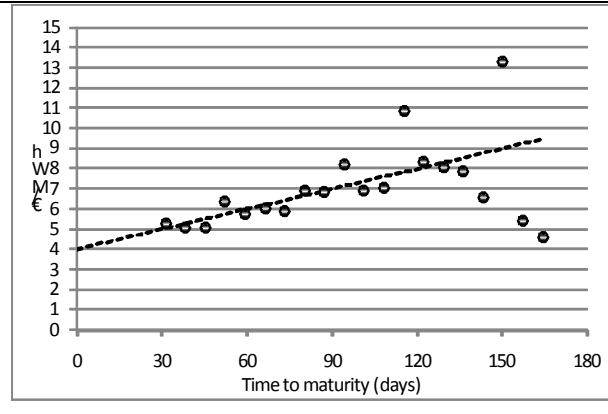

Figure 7. Standard deviation of the payoff of monthly baseload futures premia on Italian market vs time to maturity.

motion. For the specific procedure of the test and the resulting Tables, refer to Falbo et al. (2015).

On the contrary, $y_{t}$ shows a variance which is not perfectly linear with time and a residual volatility at $\tau=0$. Such a residual variance is possible because arbitrage does not hold on electricity markets. Such a result is useful to shed some light on the process of the spot prices of electricity, in particular on the process underlying $\bar{p}_{\boldsymbol{H}}$. Indeed, the fact that when the time to maturity tends to zero, the variance of $y_{t}$ does not become null, implies that the residual variance originates from $\bar{p}_{H}$.

\section{DISCUSSION AND CONCLUSIONS}

In electricity markets, since the storage of the underlying asset is not possible, arbitrage opportunities are ruled out and therefore nothing can enforce futures prices to coincide with the underlying spot price (adjusted for the interest rate and time to maturity). Consequently, risk premia show elusive behavior all over the electricity markets. We introduced and estimated a simple linear model of the risk premium. The analysis developed on the Italian case in 2008-2013 shows a possible presence of positive risk premia on an aggregate level. In particular, we found a significant risk premium of $2.2 \mathrm{c} € / \mathrm{MWH} /$ day. Such a result apparently confirms some empirical findings in the literature that there is a positive risk premium embedded in futures prices. However, the positive risk premium disappears when checking for the performance case by case of individual contracts. Moreover, the volatility of the payoffs is always positive when maturity approaches to 
Falbo et al., Discovering the effect of RES on risk premia in European electricity markets

zero and even at delivery. In particular, an affine growth of the volatility with respect to the time to maturity is found, with a value equal to about 3.95 €/MWh at maturity. Furthermore, while we found evidence that futures follow a Brownian motion, the volatility of the risk premium is not compatible with it. This may give some hints for developing new models for delivery spot prices.

\section{REFERENCES}

Bessembinder, H. and Lemmon, M., (2002), Equilibrium pricing and optimal hedging in electricity forward markets. Journal of Finance 57: 1347-1382.

Bloys van Treslong A. and Huisman R. (2010), A comment on: Storage and the electricity forward premium, Energy Economics 32: 321-324

Botterud A., Kristiansen T. and Ilic M. (2010), The relationship between spot and futures prices in the Nord pool electricity market, Energy Economics 31: 967-978

Bunn D.W. and Chen D. (2013), The forward premium in electricity futures, Journal of Empirical finance 23: $173-186$

Deng S.J. and Oren S.S. (2006), Electricity derivatives and risk management, Energy 31: 940-953

Douglas S. and Popova J. (2008), "Storage and the electricity forward premium", Energy Economics 30(4), $1712-1727$

Eydeland, A. and Geman, H. (1999), Fundamentals of electricity derivatives. In: Research Symposium Proceedings, Chicago Board of Trade, 123-146.

Falbo P., Fattore M. and Stefani S. (2010a), A new index for electricity spot prices, Energy Policy 38: 27392750

Falbo P., Felletti D. and Stefani S. (2010b), Integrated risk management for an electricity producer, European Journal of Operations Research 207: 1620-1627

Falbo P., Felletti D. and Stefani S. (2015), Electricity Futures. In The World Scientific Handbook of Futures Markets (Malliaris A. G. and Ziemba W. T. eds) World Scientific Handbook in Financial Economics Series Volume 5, 545-565

Geman, H. (2005), Commodities and Commodity Derivatives: Modelling and Pricing for Agriculturals, Metals and Energy, Wiley, Chichester.

Geman, H. and Roncoroni, A. (2006), Understanding the fine structure of electricity prices. Journal of Business 79: 1225-1262.

Huisman R. and Kilic M. (2012), Indirect storability, Expectations and risk premiums, Energy Economics 34: 892-898

Lo A.W. and Mackinlay C. (1988), Stock Market Prices do not Follow Random Walk: Evidence from a Simple Specification Test, The Review of Financial Studies, 1: 41-66.

Lucia J.J. and Torrò H. (2011), on the risk premium in Nordic electricity futures prices, International Review of Economics and Finance 20: 750-763

Mayer K., Schmid T. and Weber F. (2011), Modeling electricity spot prices - Combining mean reversion, spikes and stochastic volatility, CEFS Working Paper

Pietz M (2009), Risk Premia in the German Electricity Futures Market CEFS Working Paper No. 2009-7

Routledge, B., Seppi and D., Spatt, C. (2000), Equilibrium forward prices for commodities, The Journal of Finance 55: 1297-1338.

Shawky H.A., Marathe A., Barrett C.L. (2003), A first look at the empirical relation between spot and futures electricity prices in the United States, The Journal of Futures markets 23: 931-955

Wu D., Kleindorfer P. and J. Zhang (2002), “Optimal bidding and contracting strategies for capital intensive goods" European Journal of Operationl Research, 137(3), 657-676 